Provided for non-commercial research and education use. Not for reproduction, distribution or commercial use.

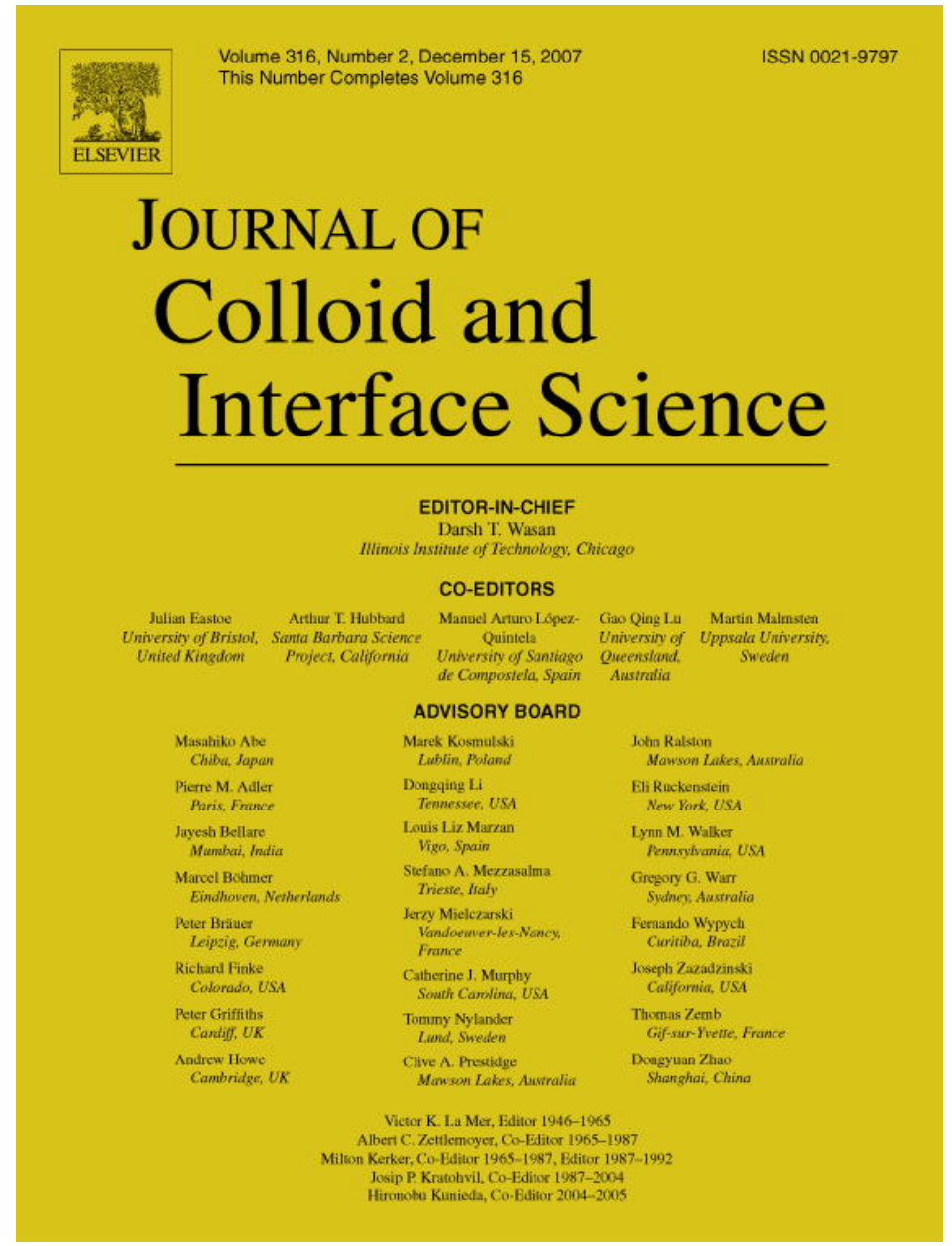

This article was published in an Elsevier journal. The attached copy

is furnished to the author for non-commercial research and education use, including for instruction at the author's institution, sharing with colleagues and providing to institution administration.

Other uses, including reproduction and distribution, or selling or licensing copies, or posting to personal, institutional or third party websites are prohibited.

In most cases authors are permitted to post their version of the article (e.g. in Word or Tex form) to their personal website or institutional repository. Authors requiring further information regarding Elsevier's archiving and manuscript policies are encouraged to visit: 


\title{
Nanoscale conformational ordering in polyanilines investigated by SAXS and AFM
}

\author{
Fabio L. Leite ${ }^{\mathrm{a}, \mathrm{b}, *}$, Mario de Oliveira Neto ${ }^{\mathrm{b}}$, Leonardo G. Paterno ${ }^{\mathrm{c}}$, Michel R.M. Ballestero ${ }^{\mathrm{b}}$, \\ Igor Polikarpov $^{\text {b }}$, Yvonne P. Mascarenhas ${ }^{\text {b }}$, Paulo S.P. Herrmann ${ }^{\text {a }}$, Luiz H.C. Mattoso ${ }^{\text {a }}$, \\ Osvaldo N. Oliveira Jr. ${ }^{\text {b }}$
}

a National Nanotechnology Laboratory for Agriculture (LNNA), Embrapa Agricultural Instrumentation (EMBRAPA), Rua XV de Novembro, 1452, P.O. Box 741, CEP 13560-970, São Carlos-SP, Brazil

b Instituto de Física de São Carlos, USP, P.O. Box 369, CEP 13560-970, São Carlos-SP, Brazil

c Departamento de Engenharia de Sistemas Eletrônicos, EPUSP, 05508-900, São Paulo-SP, Brazil

Received 16 July 2007; accepted 28 August 2007

Available online 4 September 2007

\begin{abstract}
Understanding the adsorption mechanisms in nanostructured polymer films has become crucial for their use in technological applications, since film properties vary considerably with the experimental conditions utilized for film fabrication. In this paper, we employ small-angle X-ray scattering (SAXS) to investigate solutions of polyanilines and correlate the chain conformations with morphological features of the nanostructured films obtained with atomic force microscopy (AFM). It is shown that aggregates formed already in solution affect the film morphology; in particular, at early stages of adsorption film morphology appears entirely governed by the chain conformation in solution and adsorption of aggregates. We also use SAXS data for modeling poly(o-ethoxyaniline) (POEA) particle shape through an ab initio procedure based on simulated annealing using the dummy atom model (DAM), which is then compared to the morphological features of POEA films fabricated with distinct pHs and doping acids. Interestingly, when the derivative POEA is doped with $p$-toluene sulfonic acid (TSA), the resulting films exhibit a fibrillar morphology—seen with atomic force microscopy and transmission electron microscopy — that is consistent with the cylindrical shape inferred from the SAXS data. This is in contrast with the globular morphology observed for POEA films doped with other acids.
\end{abstract}

(c) 2007 Elsevier Inc. All rights reserved.

Keywords: Self-assembly; SAXS; AFM; TEM; Nanostructures; Thin films; PANI; Adsorption and conformation

\section{Introduction}

The discovery and development of new semiconducting polymers have brought great promise for a number of technological applications [1,2] and posed new challenges in terms of understanding fundamental properties of organic materials. A key feature of these polymers is the possibility of altering their electrical and optical properties with small changes in composition or even in the experimental procedures to produce the samples [3]. Indeed, the incorporation of a substituent group in a polymer such as polyaniline or polythiophene induces considerable changes in the physicochemical properties,

\footnotetext{
* Corresponding author. Fax: +55 1633725958.

E-mail address: leite@ cnpdia.embrapa.br (F.L. Leite).
}

including solubility in organic solvents or in aqueous solutions. Samples are normally produced in the form of films, which then allows another avenue to pursue in obtaining specific properties. If films are fabricated with techniques such as the Langmuir-Blodgett (LB) [4,5] or layer-by-layer (LbL) [6,7] methods, for instance, the properties may be controlled at the molecular level. One such example was demonstrated in LB films of polyaniline and a ruthenium complex [8], in which the intimate contact between the molecules of the two components led to electrical and electrochemical properties that differed completely from those obtained for cast or spin-coated films of the same materials. The reason for these differences was elucidated with Raman spectroscopy measurements, where PANI was found to exhibit enhanced oxidation induced by the intimate contact with the ruthenium complex [9]. 
The large ability to alter polymer properties is obviously advantageous to achieve a rich variety of features. In the luminescent, semiconducting polymers such as poly( $p$-phenylenevinylenes), the emission quantum efficiency, color and polarization can be changed by mere introduction of functional groups in the polymer backbone [10]. In cases where conductivity is the property to be exploited, orders-of-magnitude changes are observed by varying the dopant concentration or $\mathrm{pH}$ [11-13]. There is a considerable disadvantage though in this ease with which polymer properties vary, particularly with regard to industrial applications. Reproducibility in the experimental results for any given type of sample or measurement is relatively poor, especially if one compares with the inorganic semiconductors. In the specific case of nanostructured films from polyanilines, several studies have shown that the adsorption mechanisms and the film properties are entirely altered by a mere change in $\mathrm{pH}$ [14]. Parent polyaniline (PANI) and its derivatives have been widely used mainly due to their remarkable electrochemical, optical, electrical and mechanical properties, and good environmental stability in the emeraldine base (EB) and emeraldine salt (ES) states $[15,16]$. These properties have been exploited in sensors $[17,18]$ and other applications $[19,20]$.

In order to identify the parameters that most affect polyaniline film properties, the morphology of LbL films has been studied in detail [21-23]. The choice of the LbL method to produce the films was based on the unique features offered by the method, which are basically the simplicity in the experimental procedures and ability to control film properties at the molecular level [24-26]. In the LbL films, polymer adsorption is in most cases driven by ionic interactions, with oppositely charged materials from aqueous solutions being deposited alternately on a solid substrate. Secondary interactions-e.g., hydrogen bonding and van der Waals-may also be important for adsorption [27], as it has been shown for polyanilines, for which H-bonding contributes even when the molecules are protonated. The layer thickness can be controlled by altering the interactions responsible for adsorption, which is carried out by changing materials and preparation conditions such as $\mathrm{pH}$, ion dopant, ionic strength and concentration of the solutions.

It was clear from the morphological studies mentioned above that film properties also depended strongly on the conformation of the polymer in solution. Access to this type of information is not straightforward because the polyaniline solutions are polydisperse. Here we employ small angle X-ray scattering (SAXS) to investigate the properties of parent PANI, poly $(o-$ methoxyaniline) (POMA) and poly(o-ethoxyaniline) (POEA) in solution at various pHs and doping acids. SAXS is useful to probe the material structure on a scale from 0.05 to $2000 \AA$ [28, 29], as it may provide statistically meaningful measurements of total volumes, surface areas and scattering centers [30]. Knowledge about the external surface structure of the polymer can be obtained by measurements of the scattering intensity $I(q)$ versus the scattering vector modulus. We then study the influence from the conformation of polymers in solution on the properties of nanostructured films. Parameters such as roughness, aggregation, and fractal dimension were used to interpret the data.

\section{Experimental details}

PANI, POMA, and POEA were chemically synthesized according to the methods described in Ref. [31] (Fig. 1). Solutions

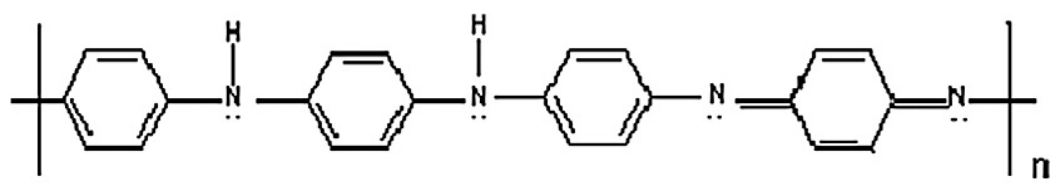

(a)

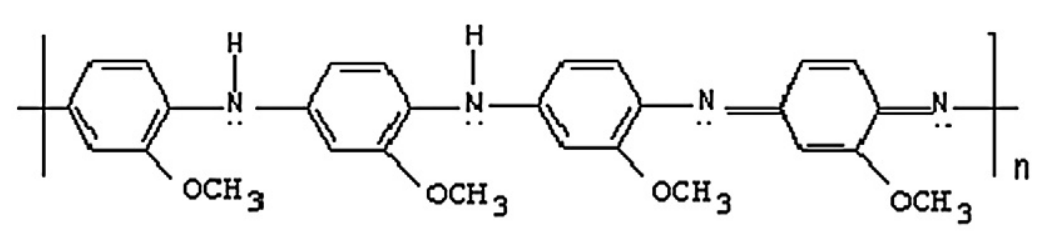

(b)

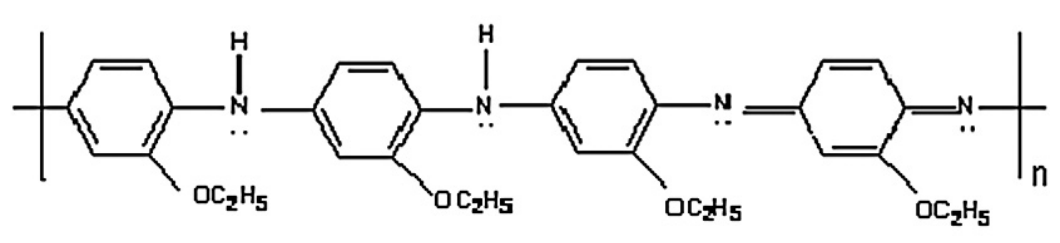

(c)

Fig. 1. Emeraldine base form of (a) PANI, (b) POMA, and (c) POEA. 
were prepared by dissolving the dedoped polymers (EB) in water and dimethyl acetamide (DMAc) with a concentration of $3 \mathrm{~g} \mathrm{~L}^{-1}$. The solutions were left stirring overnight and then filtered obtaining a final concentration $\approx 2.5 \mathrm{~g} \mathrm{~L}^{-1}$. The polymers in these solutions were doped with $\mathrm{HCl}$, with the $\mathrm{pH}$ adjusted at selected values between 1.5 and 10, as indicated. For the study of different dopants, POEA was doped with one of the following acids: $p$-toluenesulfonic acid ( $p$-TSA), camphorsulfonic acid (CSA), sulfanilic acid (SAA), and hydrochloric ( $\mathrm{HCl})$ acid. The doping acids were all purchased from Sigma-Aldrich, and used as received.

The SAXS experiments were conducted at the National Synchrotron Light Laboratory (LNLS), Campinas, Brazil, using a monochromatic X-ray beam $(\lambda=1.488 \AA$ ) , which focuses the beam horizontally, and a one dimensional position-sensitive $\mathrm{X}$ ray detector to record the scattering intensity. To perform the SAXS measurement, the aqueous solution was placed in a flat cell and sealed. The SAXS curves were normalized with respect to (i) the decreasing intensity of the coming synchrotron beam and (ii) the sample absorption. The SAXS intensity produced by the solvent (water and DMAc) was measured and subtracted from the total scattering intensity before the analysis.

The scattered intensity was measured over the scattering vectors, $q=(4 \pi / \lambda) \sin \theta$, where $2 \theta$ is the total scattering angle and $\lambda$ is the wavelength generated from the rotating anode source which was monochromatized by a crystal monochrometer. In Guinier's theory, the X-ray scattering intensity from the sample $(I)$ depends on the number of particles per unit volume $\left(N_{\mathrm{p}}\right)$, the electron density difference between particles and the medium $(\Delta \rho)$, volume of the particle $(v)$, radius of gyration $\left(R_{\mathrm{g}}\right)$ and the scattered intensity of a single electron $\left(I_{\mathrm{e}}\right)$ [32].

$I(q)=I_{\mathrm{e}}(q) N_{\mathrm{p}}(\Delta \rho v)^{2} \exp \left(\frac{-R_{\mathrm{g}}^{2}}{3} q^{2}\right)$.

In a Guinier plot, $\ln I(q)$ vs $q^{2}(I(q) \rightarrow I(0))$, the slope of the linear region allows $R_{\mathrm{g}}$ to be obtained [33]. Since solutions containing particles of different sizes (polydisperse) show several linear regions in the Guinier plot, in order to generate low resolution models we considered only the SAXS curve from the last linear region. This region has a high minimum angle and therefore information on the large distances in the molecules is lost [34]. This was performed as an attempt to include the information due to the smallest particles in solution as if the system were monodisperse (three-dimensional models).

In the absence of interference effects, a Fourier transform connects the normalized particle form factor (and hence $I(q)$ ) to the pair distance distribution function, $p(r)$, the probability of finding a pair of small elements at a distance $r$ within the entire volume of the scattering particle as [35]

$p(r)=\left(\frac{1}{2 \pi^{2}}\right) \int_{0}^{\infty} I(q) q r \sin (q r) d q$.

This function provides information about the shape of the scattering particle as well as its maximum dimension, $D_{\max }$, accounted for a certain $r$ value where $p(r)$ goes to zero. Moreover, the particle radius of gyration, $R_{\mathrm{g}}$, value is given by [36]
Table 1

$R_{\mathrm{g}}$ for the polyaniline and its derivates in solution at distinct $\mathrm{pH}$ values $(\mathrm{HCl})$

\begin{tabular}{llll}
\hline Material $\mathrm{pH}$ & $\frac{R_{\mathrm{g}}(\AA)}{}$ \\
\cline { 3 - 4 } & $\operatorname{Max}$ & Min \\
\hline
\end{tabular}

Region I-aggregates $\left(q^{2} \leqslant 0.0016\right)$

\begin{tabular}{|c|c|c|c|}
\hline \multirow[t]{3}{*}{ POEA } & 1.5 & \multicolumn{2}{|l|}{ Precipitate } \\
\hline & 3.0 & 112.9 & 51.9 \\
\hline & 5.0 & 60.8 & 37.6 \\
\hline & 10.0 & 77.2 & 45.9 \\
\hline \multirow{4}{*}{ POMA } & 1.5 & Precipitate & \\
\hline & 3.0 & 77.1 & 56.8 \\
\hline & 5.0 & 47.9 & 31.1 \\
\hline & 10.0 & 65.7 & 42.9 \\
\hline \multirow[t]{4}{*}{ PANI } & 2.5 & Precipitate & \\
\hline & 3.0 & 87.4 & 59.7 \\
\hline & 5.0 & 94.4 & 48.6 \\
\hline & 10.0 & 52.8 & 41.2 \\
\hline \multicolumn{2}{|c|}{ Region II-smallest particles $\left(q^{2} \geqslant 0.0016\right)$} & $R_{\mathrm{g}}^{\text {Guinier }}$ & $R_{\mathrm{g}}^{\mathrm{GNOM}}$ \\
\hline POEA & 3.0 & $39.2 \pm 2.7$ & $42.5 \pm 0.6$ \\
\hline & 5.0 & $31.5 \pm 3.0$ & $36.9 \pm 0.8$ \\
\hline & 10.0 & $28.8 \pm 2.9$ & $32.0 \pm 0.8$ \\
\hline POMA & 3.0 & $39.1 \pm 2.0$ & $41.4 \pm 0.6$ \\
\hline & 5.0 & $29.8 \pm 2.8$ & $31.9 \pm 0.3$ \\
\hline & 10.0 & $26.2 \pm 1.8$ & $28.2 \pm 0.3$ \\
\hline PANI & 3.0 & $33.3 \pm 1.3$ & $34.0 \pm 0.3$ \\
\hline & 5.0 & $30.3 \pm 1.9$ & $34.3 \pm 0.4$ \\
\hline & 10.0 & $31.2 \pm 2.3$ & $35.8 \pm 1.4$ \\
\hline
\end{tabular}

$R_{\mathrm{g}}^{2}=\frac{\int_{0}^{D_{\max }} p(r) r^{2} d r}{2 \int_{0}^{D_{\max }} p(r) d r}$.

In this work, we make use of the GNOM program [37] to calculate $p(r)$ and estimate the radii of gyration $\left(R_{\mathrm{g}}^{\mathrm{GNOM}}\right)$ (see Table 1). The smearing effect, caused by the length of the detector window, was corrected and the distance distribution function $p(r)$ was calculated. The dummy atom model (DAM) was generated with the program DAMMIN, which employs simulated annealing to obtain a model that minimizes the discrepancy between the theoretical and experimental curves [38]. For each structure, several models were tried, with no symmetry imposed, and an average DAM was calculated using the program DAMAVER [39]. The 3D-envelopes were visualized with VMD software [40].

The nanostructured films were prepared with POEA. At $\mathrm{pH} 3$, POEA is not fully protonated, which leads to a chemical structure that is a mixture of emeraldine salt and base forms. For POEA, a few minutes are sufficient to form a stable and continuous layer [21]. Fractal dimension and film roughness were analyzed on films obtained with immersion times between 1 and $180 \mathrm{~s}$ at $\mathrm{pH} 10$ (EB). To analyze the $\mathrm{pH}$ effect on film morphology only the initial adsorption stage was considered, and therefore the immersion time was only $3 \mathrm{~s}$, for solutions with $\mathrm{pH}$ varying from 3 to 10 . The influence from the dopant was studied with films produced with POEA solutions at $\mathrm{pH} 3$, immersion time of $180 \mathrm{~s}$ and 4 dopant acids (CSA, SAA, $\mathrm{HCl}$ and TSA). Substrates were prepared with optical glass slides $(1 \times 10 \times 30 \mathrm{~mm})$ previously cleaned in $\mathrm{H}_{2} \mathrm{SO}_{4} / \mathrm{H}_{2} \mathrm{O}_{2}, 7: 3 \mathrm{v} / \mathrm{v}$ solutions for $1 \mathrm{~h}$, followed by extensive washing in ultra-pure water. The slides were then immersed into 
a $\mathrm{H}_{2} \mathrm{O} / \mathrm{H}_{2} \mathrm{O}_{2} / \mathrm{NH}_{4} \mathrm{OH}$ 5:1:1 v/v solution for $40 \mathrm{~min}$ and again washed with large amounts of ultra pure water. The growth of the POEA layers was monitored by measuring the UV-vis absorption spectrum with a UV-vis spectrophotometer Shimadzu UV-1601 PC.

The POEA solution was also transferred onto a transmission electron microscope (TEM) copper grid for TEM observation on a Philips CM 200 operating at $200 \mathrm{kV}$. Atomic force microscopy (AFM) images were taken in a Topometrix microscope, model Discoverer TMX 2010, using silicon nitride tips (V shape) with spring constant of $0.06 \mathrm{~N} / \mathrm{m}$ (nominal value). All images were obtained in the contact mode at a scan rate of
$2 \mathrm{~Hz}$. The root-mean-square roughness, $R_{\mathrm{ms}}$, and the surface fractal dimension were calculated using WSxM 4.0 software from Nanotec Electronica S.L. (Copyright (C) November 2003) and scanning probe image processor (SPIP) version 3.1.0.1 from Image Metrology A/S 2003.

\section{Results and discussion}

\subsection{Polyanilines in solution investigated by SAXS}

Processing parameters are known to affect film morphology to a great extent, and there is evidence that some differences

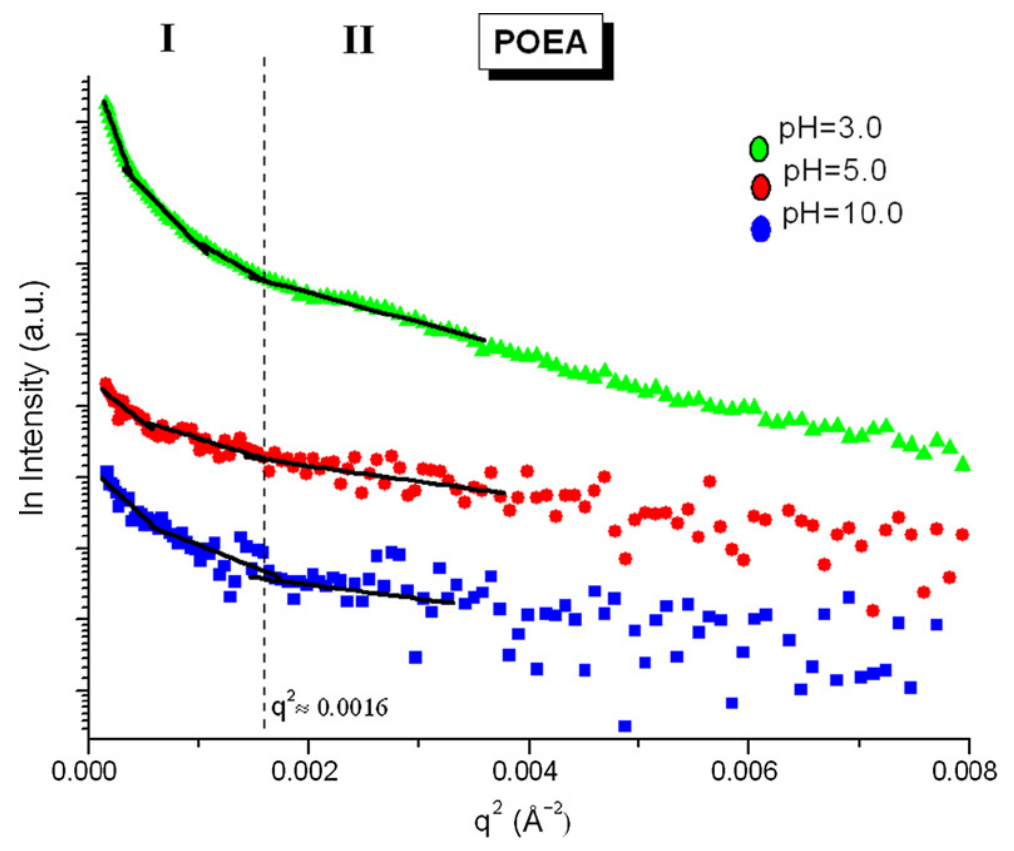

(a)

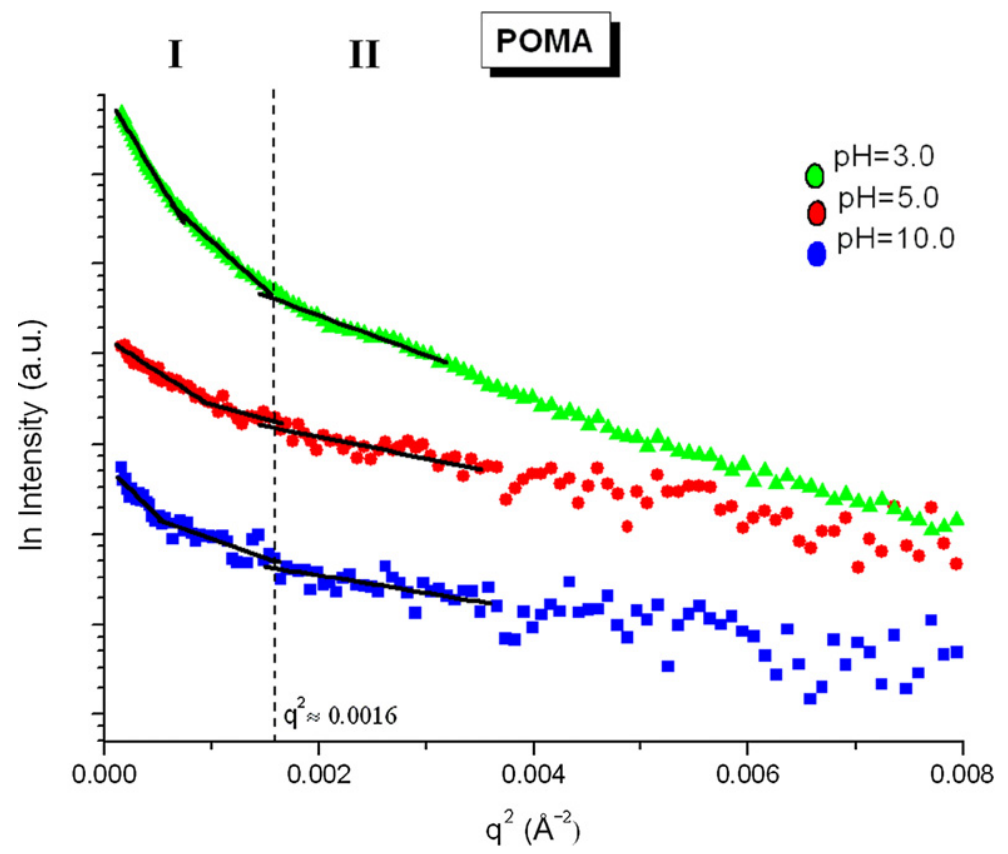

(b)

Fig. 2. $\ln I$ vs $q^{2}$ curves for (a) POEA, (b) POMA, and (c) PANI in distinct pH values, which show two linear profiles, demarcated by the dashed line. 


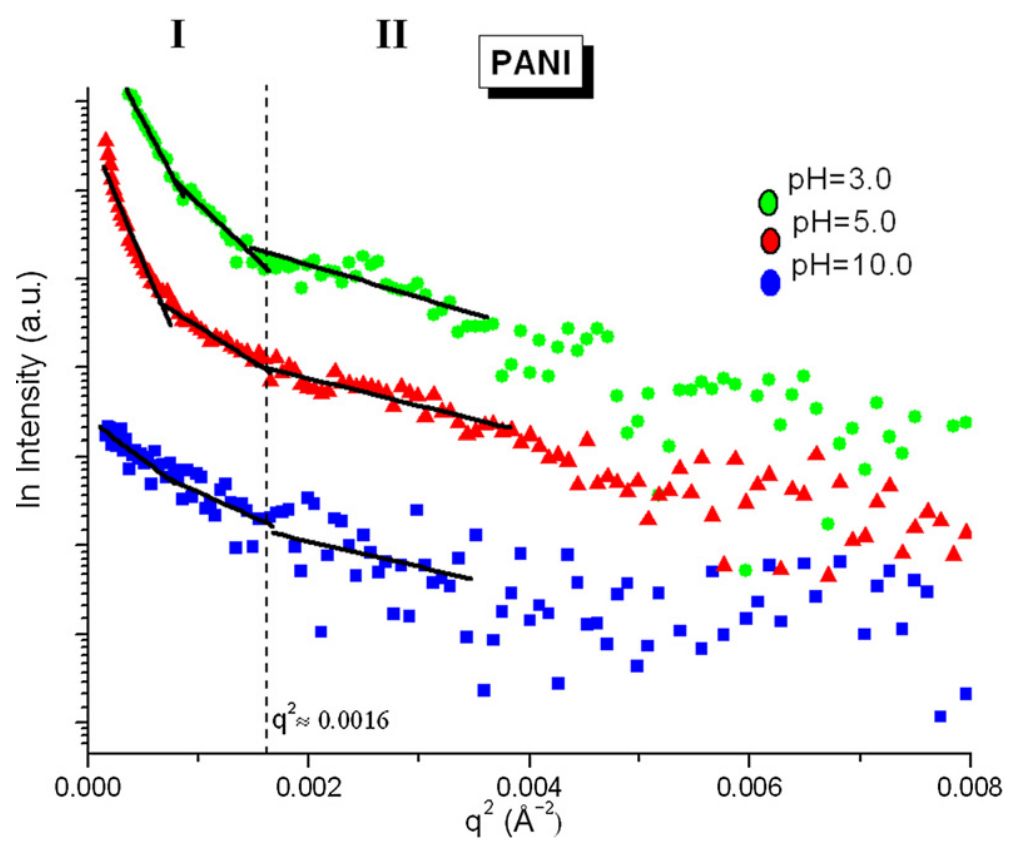

(c)

Fig. 2. (continued)

are already present in the solution used to produce the films. To elucidate this behavior, SAXS analysis was performed for polyanilines in various types of solution. Fig. 2 shows Guinier plots, $\ln I$ vs $q^{2}$, for POMA, POEA, and PANI solutions at distinct $\mathrm{pHs}$, namely 3.0, 5.0, and 10.0, where considerable heterogeneity is seen in all samples. With a Guinier plot one is able to calculate $R_{\mathrm{g}}$ since $q R_{\mathrm{g}}$ should be around 1, i.e., $q_{\text {max }} R_{\mathrm{g}} \leqslant 1.5$. Two requirements to apply Guinier's law are that the particles (scattering centers) should all have the same size (monodisperse) and be far from each other to avoid interparticle scattering. Because neither of these conditions applies to the polymer samples, the analysis based on the Guinier region only gives an estimate of the scattering center sizes [41]. Two or three linear regions can be identified in Fig. 2, from which upper and bottom limits of aggregation radii may be estimated for the aggregated particle sizes.

Table 1 shows the $R_{\mathrm{g}}$ values calculated with the procedures established in Ref. [42] where we used two regions of the curve, referred to as regions I $\left(q^{2} \leqslant 0.0016\right)$ and II $\left(q^{2} \geqslant 0.0016\right)$. A careful investigation of the Guinier plots reveals two linear regimes: I-a short linear profile at very low $q$ values, and IIa wider linear profile. Since the $q$ values probe the structural features at various length scales, the larger value of the slope of the linear region I (compared to II) indicates a larger size of the scatterers, i.e., chain aggregates [42]. In region I, $R_{\mathrm{g}}$ of the aggregates increases with decreasing $\mathrm{pH}$, since aggregation is precluded by the charges incorporated upon adding acid to the solution. However, at low pHs $(\leqslant 2.5)$, the solution becomes unstable and starts to precipitate. This explains why $R_{\mathrm{g}}$ of the structures in Table 1 increases as the $\mathrm{pH}$ was decreased from 5.0 to 3.0. Considering data for other $\mathrm{pHs}$, we conclude that the best tradeoff between solubility and aggregation upon dedoping the polymers is attained at $\mathrm{pH} \approx 5.0$. The values of $R_{\mathrm{g}}$ in region II from Guinier analysis are comparable to those obtained from the shape factors $\left(R_{\mathrm{GNOM}}\right)$. Therefore, we may infer that in dilute solutions of conducting polymers, chain conformation can be estimated by SAXS.

Fig. 3 shows the low-resolution particle shape for the polyanilines molecules in solution, determined from the experimental data using the ab initio procedure [43]. A less-packed,

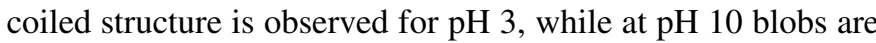
formed, which are consistent with the radii of gyration in Table 1 (region II), and with the literature according to which a more extended structure is obtained by increasing the doping level [44].

The conformation of polyaniline molecules in solution also depends on the doping acid [45-47], which is illustrated here for POEA doped in $\mathrm{pH} 3.0$ with four acids, namely $\mathrm{HCl}$, CSA, SAA, and TSA. Fig. 4 shows low-resolution envelopes obtained with the same procedures as for those in Fig. 3. A less-packed, coiled conformation was observed for $\mathrm{HCl}$ and $\mathrm{CSA}$, while for SAA and TSA the conformation is rod-like and cylindrical, respectively. Counterions of organic acids are strongly bound to the polymeric chain because they are less solvated. Consequently, the charges in the polymeric chains are more effectively screened and the polymer appears almost like a neutral polymer. In this situation the polymeric chains assume a rodlike conformation which results in aggregates of greater radii of gyration. On the other hand, ions easily solvated in water, as is the case of chloride, are less effective in screening the polyion charges, and therefore the polymeric chains assume a more extended coil-like conformation due to the intra and inter molecular electrostatic repulsion. The consequences for the film morphology of these distinct conformations will be discussed in the next section.

Another parameter that may be obtained from the SAXS data is the fractal dimension [48] of the molecular structures in solution. As $I(q)$ follows a power law (Eq. (4)) [49], the fractal 


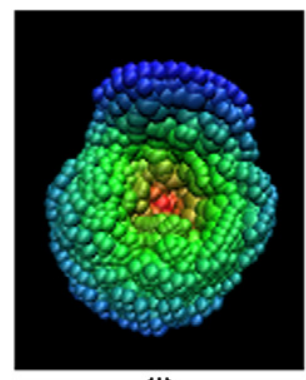

(i)

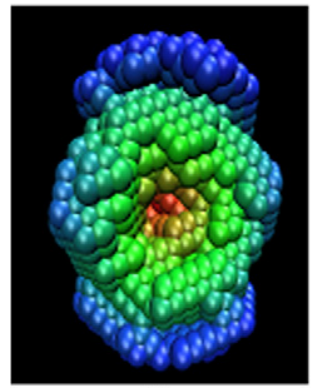

(i)

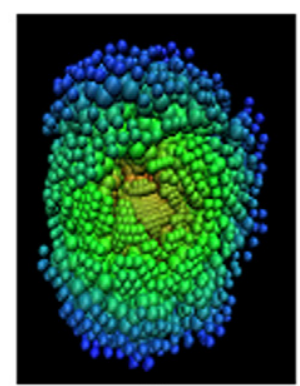

(i)

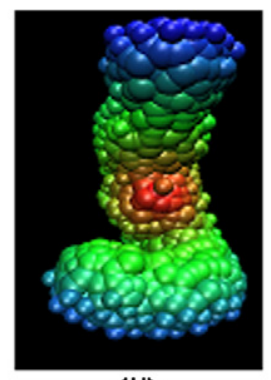

(ii)

(a)

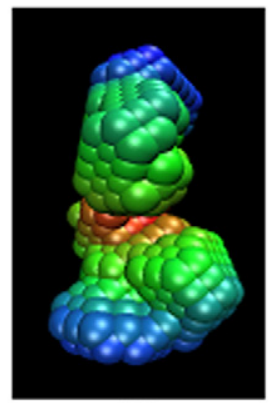

(ii)

(b)

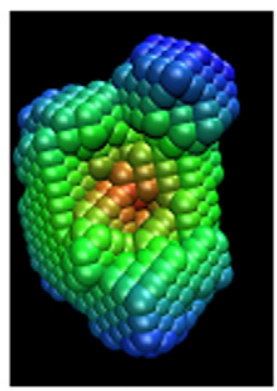

(ii)

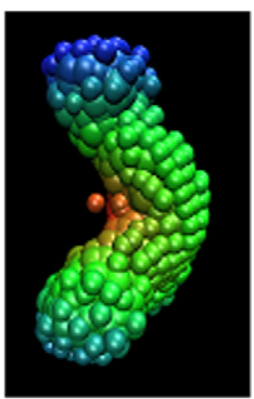

(iii)

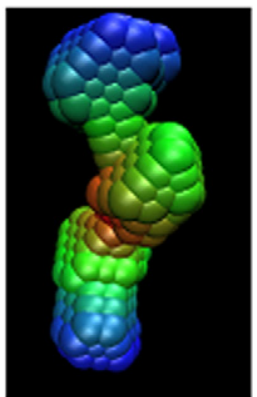

(iii)

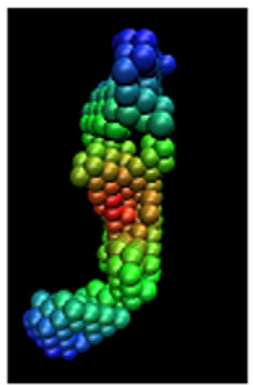

(iii)

(c)

Fig. 3. Average DAM for (a) POEA, (b) POMA, and (c) PANI in (i) pH 10.0, (ii) pH 5.0, and (iii) pH 3.0 (HCl).

dimension may be determined from the SAXS profile, analyzing the power-law profile $\left(q>0.01 \AA^{-1}\right)$ [42] shown in Fig. 5. In this region, the scattering profiles do not depend on the shape of the scattering units.

$$
I(q) \propto q^{-\alpha},
$$

where $I$ is the scattered intensity, $q$ is the modulus of the scattering vector, and the exponent $\alpha$ is related to the fractal dimension of the scattering particles. The slope of the linear region in $\log I(q)$ vs $\log (q)$ plot gives the exponent $\alpha$, the dimensionality of the scattering object.

Systems with fractal behavior are characterized by geometric auto-similarity in a given region, i.e., the structure is independent of the observation scale size [50]. The fractal dimension helps quantify properties such as mass $(m)$ and surface area $(A)$, since a fractal object varies with the radius of gyration [51]. The slope $(\alpha)$ of $\log I(q)$ vs $\log q$ curves in the linear region was calculated, with linear regression analysis, leading to fractal dimensions $\left(D_{\mathrm{f}}\right)$. For $\alpha$ between 1 and $3, D_{\mathrm{f}}$ is determined with Eq. (5) and the material is characterized as mass fractal $\left(D_{\mathrm{f}}^{\mathrm{m}}\right)$ in a three-dimensional space. The so-called surface fractals $\left(D_{\mathrm{f}}^{\mathrm{s}}\right)$ have $\alpha$ between 3 and 4 , with the fractal dimension estimated with Eq. (6) [52]. Mass fractals are scattering centers whose mass increases proportionally to the volume while surface fractals are dense scattering centers associated with surface roughness. In Eq. (6), if $D_{\mathrm{f}}=2.0$ we obtain the well-known Porod's law $I(q) \propto q^{-4}$ for nonfractal structures with smooth interfaces [52].

$D_{\mathrm{f}}^{\mathrm{m}}=|\alpha|$,

$D_{\mathrm{f}}^{\mathrm{s}}=-|\alpha|+6$.

The slopes in the linear region were calculated as -2.7 , -2.4 , and -2.6 for PANI-EB, POEA-EB, and POMA-EB (pH 10.0), respectively, corresponding to mass fractals. Values 
of $\alpha$ for PANI, POEA, and POMA at $\mathrm{pH} 3.0$ were $-1.7,-1.3$, and -1.4 , respectively. Therefore, in solution all polyanilines exhibited mass fractals. As we shall see with the AFM data for nanostructured films, surface fractals are observed (see later Fig. 6). Typically, $\alpha=2$ for Gaussian chains, platelets or discs, or sheet-like lamellar objects; $\alpha=1$ for rigid rods, and $\alpha=3$

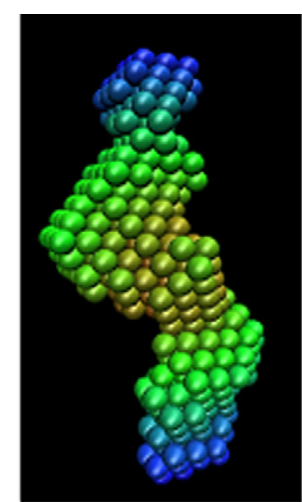

(a)

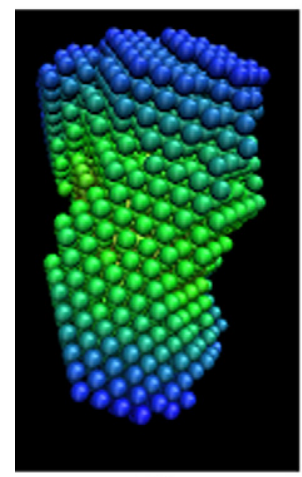

(c)

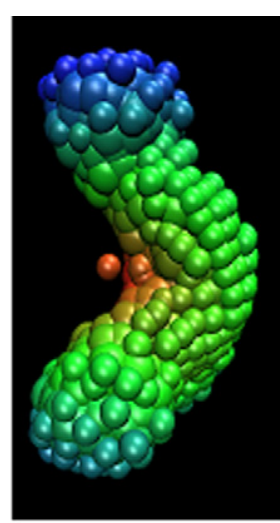

(b)

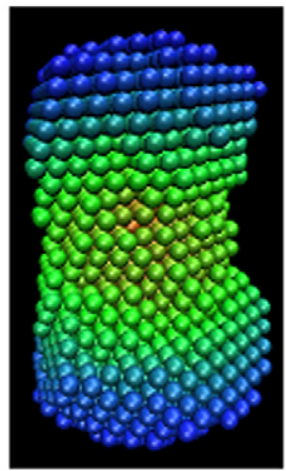

(d)
Fig. 4. Dummy residues model for POEA doped with (a) CSA $\left(R_{\mathrm{g}}=28.8 \AA\right.$ A $)$, (b) $\mathrm{HCl}\left(R_{\mathrm{g}}=32.0 \AA\right)$, (c) SAA $\left(R_{\mathrm{g}}=36.4 \AA\right)$, and (d) $\mathrm{TSA}\left(R_{\mathrm{g}}=36.9 \AA\right)$ (pH 3.0). for tight compact structures. The values of $\alpha$ for the $q$-range used $(0.01<q<0.1 \AA)$ indicate that the polymers adopt a relatively more compact blob-like structure when undoped ( $\mathrm{pH} 10)$, while in the doped state they exhibit Gaussian-like chain structures.

There are two aggregation regimes depending on the limiting factor for the aggregation: diffusion-limited cluster aggregation (DLCA) and reaction-limited cluster aggregation (RLCA) $[53,54]$. For DLCA, aggregation is led by cluster diffusion with a fractal dimension $D_{\mathrm{f}} \approx 1.7-1.8$. Particles under RLCA repel each other, growing more-compact aggregates with a limit fractal dimension of $D_{\mathrm{f}} \approx 2.0-2.1$. A continuous transition between both regimes has also been reported, e.g., charged systems as a function of the range of the interactions [55,56]. Experiments have recently shown that aggregates grown in a 50/50 mixture of positive and negative particles show low-density fractal structures compared to those obtained from the universal regimes, $D_{\mathrm{f}} \approx 1.2-1.4$ [57]. For our case, only PANI-ES is under the DLCA regime, the others showed low-density fractal structures i.e., the inner structure of the clusters was indeed fractal and the dimension characterizing it was lower than for DLCA [58]. In uncharged systems, POEA and POMA are under the RLCA regime, while for PANI the fractal dimension is higher than the typical values for diffusive aggregation.

\subsection{Film morphology}

The influence from the state of aggregation, doping and conformation in solution on the film properties has been mentioned in previous studies $[59,60]$. The question that then arises is whether a direct relationship can be established between the conformations in solution and in the solid film. The LbL technique allows film preparation within short-time intervals, and therefore it is important to probe the kinetics of polymer adsorption to optimize the time of film fabrication. For POEA, a few minutes are sufficient to form a stable and continuous layer [21]. We observed the film morphology of POEA films

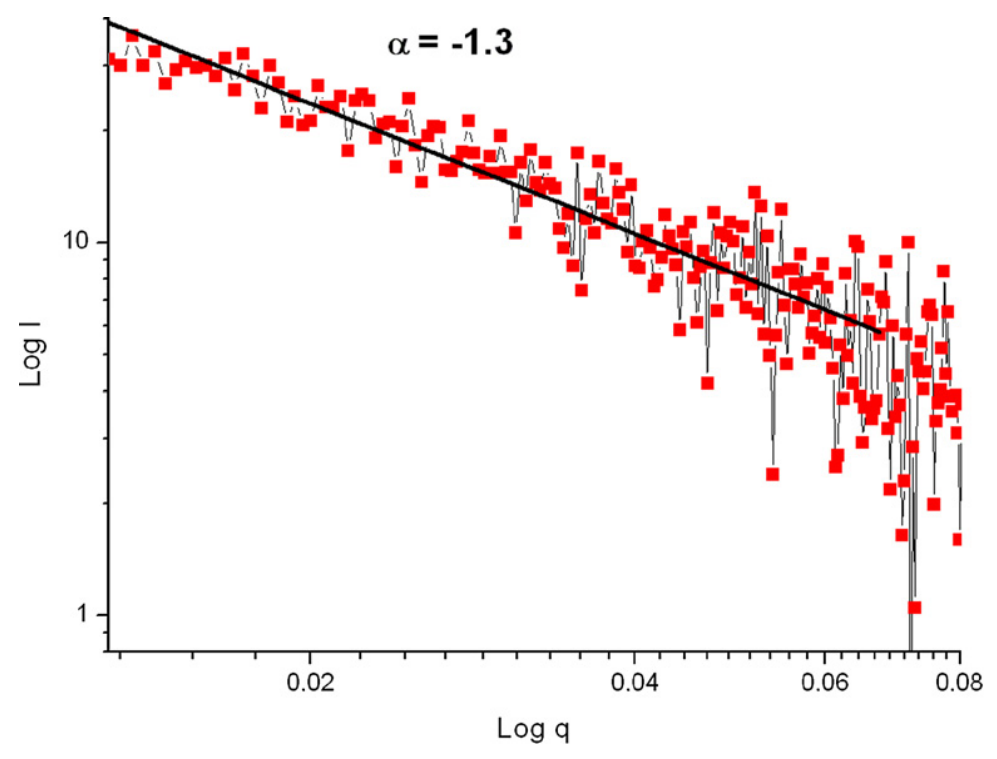

Fig. 5. $\log I$ vs $\log q$ typical curve in the power-law region for POEA-ES (pH 3.0). 


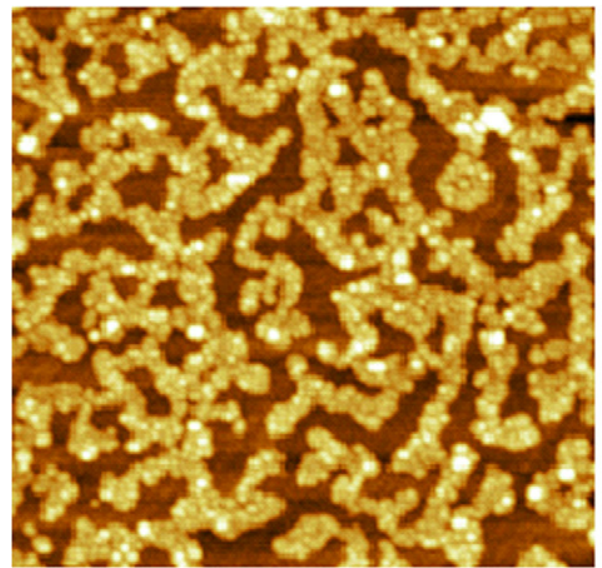

(a)

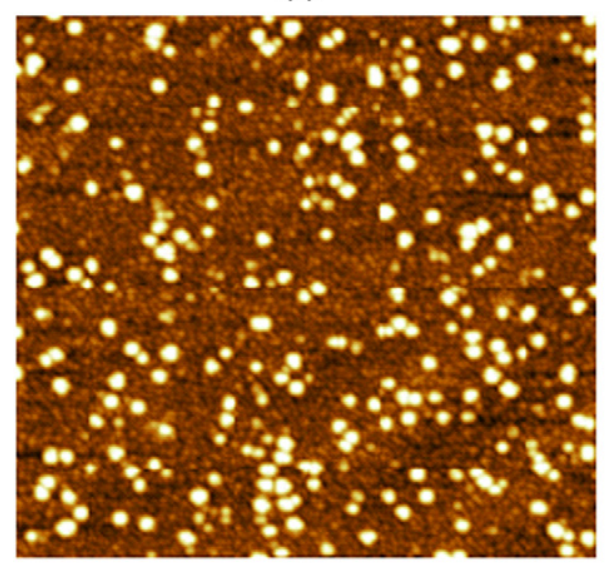

(c)

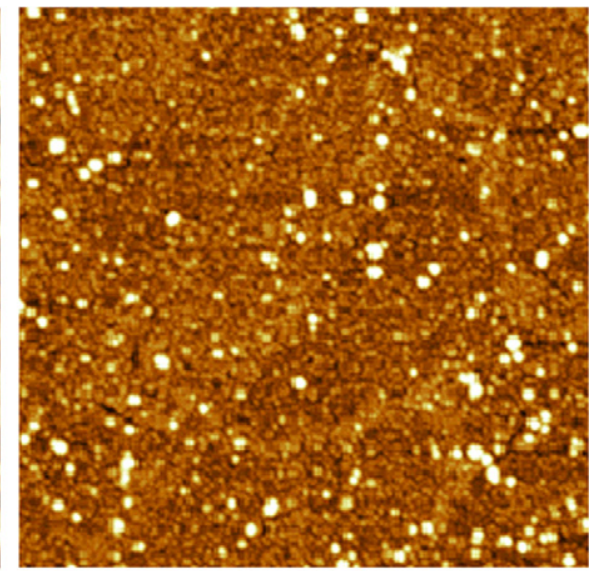

(b)

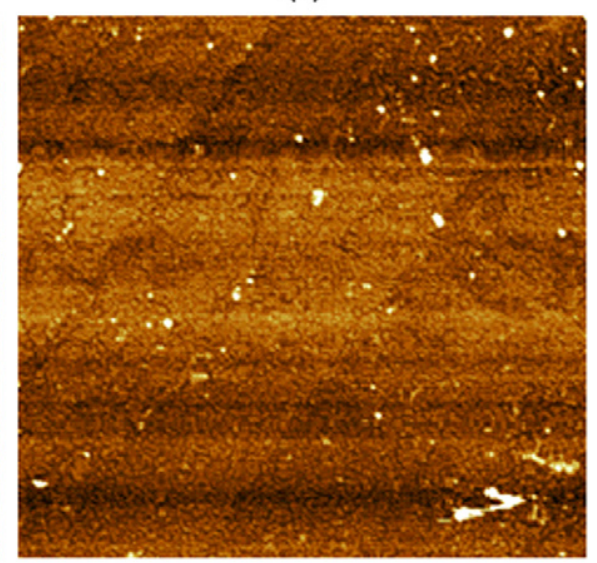

(d)

Fig. 6. AFM images $(10 \times 10 \mu \mathrm{m})$ of POEA-EB (pH 10.0) for immersion times of (a) $1 \mathrm{~s}\left(R_{\mathrm{S}}=69 \pm 25 \AA ; D_{\mathrm{f}}=2.39\right)$, (b) $3 \mathrm{~s}\left(R_{\mathrm{S}}=74 \pm 30 \AA ̊ ; D_{\mathrm{f}}=2.25\right)$, (c) $5 \mathrm{~s}$ $\left(R_{\mathrm{S}}=96 \pm 30 \AA ; D_{\mathrm{f}}=2.34\right)$, and (d) $180 \mathrm{~s}\left(D_{\mathrm{f}}=2.23\right) . R_{\mathrm{t}}$ is $200 \AA$, calculated by SEM.

at very early stages of adsorption with the same solutions used in SAXS experiments. The images are shown in Fig. 6, for adsorption times of $1,3,5$, and $180 \mathrm{~s}$. The size of the globules was determined from the images, but after correcting for the effects from a tip having similar size as the particles [61-63]. The correction was made using a geometric relation:

$R_{\mathrm{s}}^{\mathrm{t}} \approx \frac{L^{2}}{16 R_{\mathrm{t}}}$

where $R_{\mathrm{s}}^{\mathrm{t}}$ is the true radius of the particle, $R_{\mathrm{t}}$ is the tip radius, and $L$ is the apparent size.

The radii of the globules in the film imaged in Fig. 6 were $69 \pm 25,74 \pm 30$, and $86 \pm 30 \AA$, for 1,3 , and $5 \mathrm{~s}$, respectively. We did not calculate the size for $180 \mathrm{~s}$ because further aggregation takes place and no comparison can be made with POEA conformation in solutions (see below). These radii are compared with the aggregate size in solutions. To estimate the latter, we assumed that the particles in solution are spherical, thus allowing $R_{\mathrm{S}}$ (radius of globules) to be calculated using [64]:

$R_{\mathrm{S}}=(5 / 3)^{1 / 2} R_{\mathrm{g}}$.

The radii of gyration (GNOM) of the smallest particles for POEA-EB was $42.5 \AA$ (Table 1), which leads to a $R_{\mathrm{s}}=54 \AA$ using Eq. (6), in agreement with the particle size in the AFM images for short adsorption times (ca. 1 s, Fig. 6a). For larger aggregates, i.e., $50 \leqslant R_{\mathrm{g}} \leqslant 77 \AA$, the radius of the globules $\left(R_{\mathrm{S}}\right)$ obtained with Eq. (6) was $65 \leqslant R_{\mathrm{S}} \leqslant 99 \AA$, consistent with the particle size in the AFM images for an adsorption time of $3 \mathrm{~s}$ (Fig. 6b). Therefore, at short immersion times $(t \leqslant 3 \mathrm{~s})$ the smallest POEA aggregates (DAM) adsorb on the substrate, followed by further aggregation. In addition, within $3 \mathrm{~s}$ of adsorption nucleation appears to be complete, followed by growth of globules due to incorporation of additional polymer chains. For longer periods of adsorption, diffusion along the surface causes the film morphology to become flatter [21]; indeed, a less rough film is formed at the end of $180 \mathrm{~s}$ of immersion (Fig. 6d). As expected, the same applies to POMA and PANI, since the solutions are similar (emeraldine base). We also calculated the fractal dimension for the POEA films, according to the methods used in Ref. [21]. The values obtained varied from 2.23 to 2.39 , and therefore all films presented surface fractals $\left(D_{\mathrm{f}}>2.2\right)$, i.e., rough with uniformly dense structures, in contrast to those values for solutions which were characteristic of mass fractals.

The effect from $\mathrm{pH}$ was analyzed by producing POEA films adsorbed with an immersion time of $3 \mathrm{~s}$ at several $\mathrm{pHs}$, with the AFM images shown in Fig. 7. In general, the film morphology is globular, with globules ranging from 200 to $1000 \AA$ in di- 


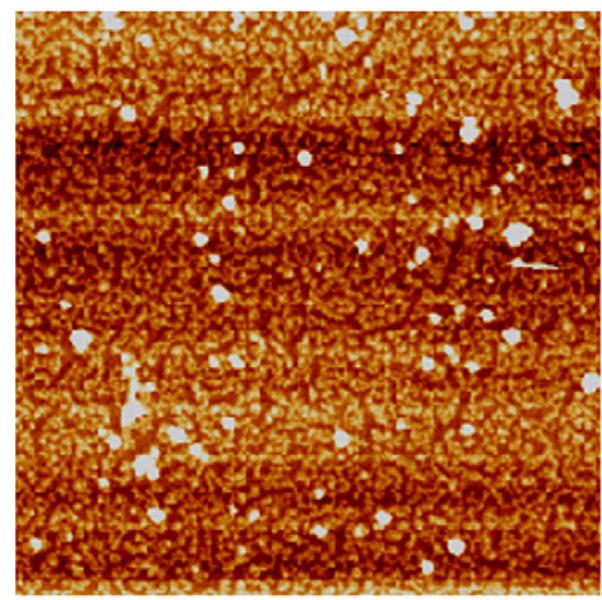

(a)

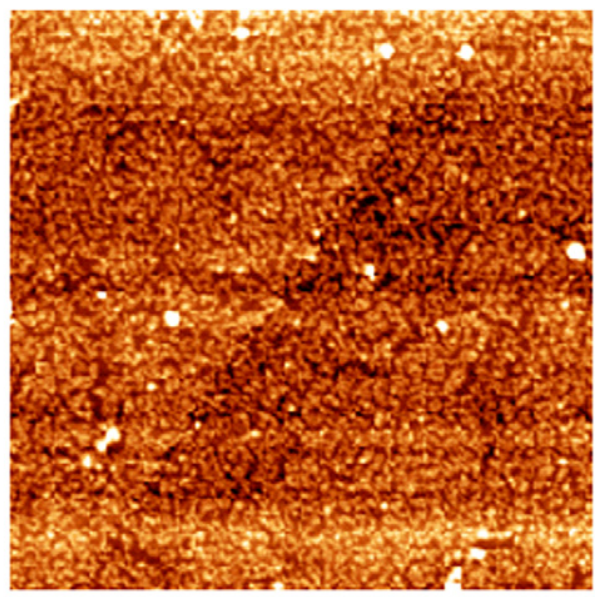

(b)

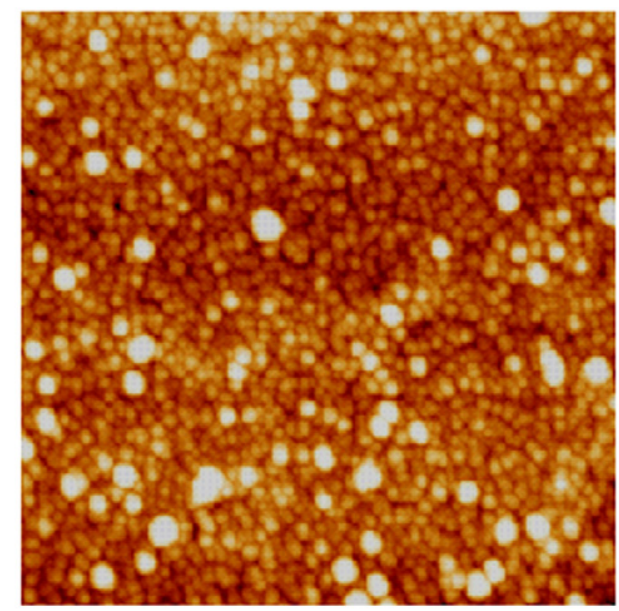

(c)

Fig. 7. AFM images of POEA at $3 \mathrm{~s}$ on (a) $\mathrm{pH} 3.0$, (b) $\mathrm{pH} 5.0$, and (c) $\mathrm{pH} 10.0(5 \times 5 \mu \mathrm{m})$.

ameter for $\mathrm{pH} 3$ and from 600 to $2500 \AA \AA$ for $\mathrm{pH} 10$. The larger diameter for the higher $\mathrm{pH}$ is due to aggregation in solution (see Table 1), which changes diffusion and the adsorption rates on the surface, leading to large irregularities in the films. At $\mathrm{pH} 3$ (doped), the interactions between chains and with the surface are less significant, favoring formation of defects (small tunnels) and less condensed packing of polymer chains with less aggregates (Fig. 7a). In this model, charged polyelectrolytes form thin films as the charged molecules adsorbed create a potential barrier that prevents more molecules from adsorbing, thus yielding flat, ultra-thin films [65].

The AFM images also exhibit wormlike structures representing aggregates made of several blobs for $\mathrm{pH} \geqslant 5.0$, as illustrated in Fig. 6a. This aggregation occurs on the sample surface, within very short times. Some of these structures could already exist in solution, as the aggregates depicted in Table 1 indicate. A possible mechanism for the formation of the structures appearing in Fig. 7 is as follows. Chains collapse to form blobs due to hydrophobic interactions and form a compact core, which adsorb as a layer (Fig. 7b), whereas protonated polyaniline adopts an extended conformation due to the Coulomb repulsion and forms several tunnels (Fig. 7a). Thus, for $\mathrm{pH} \leqslant 3.0$,
POEA structures are more extended than for higher $\mathrm{pH}$, both on the surface and in solution. In summary, although details of conformation may be lost due to adsorption and solvent evaporation, features of the micro and nano-conformation are preserved on the films.

As observed in the SAXS experiments, the chemical structure of the dopant counter-ions has a strong influence on the properties of POEA solutions, and the same influence can be seen on the film fabrication process. In order to investigate such an effect, POEA films were produced with solutions containing different doping acids. We could verify by UV-vis spectroscopy, whose results are shown in Fig. 8, that the amount of POEA, taken as proportional to the absorption, depends on the acid used for film deposition. Although POEA is doped in all films as confirmed by the presence of the polaronic band at $700-800 \mathrm{~nm}$, the amount of adsorbed POEA on glass increased in the following order: TSA $>$ SAA $>\mathrm{CSA}>\mathrm{HCl}$, which is consistent with Paterno and Mattoso [66] who observed higher adsorption for TSA-doped POEA. The larger adsorption for POEA doped with the bulkiest anions may be explained by the low mobility and low solvation of these counter-ions, causing a higher screening effect of the charges in POEA chains. This 


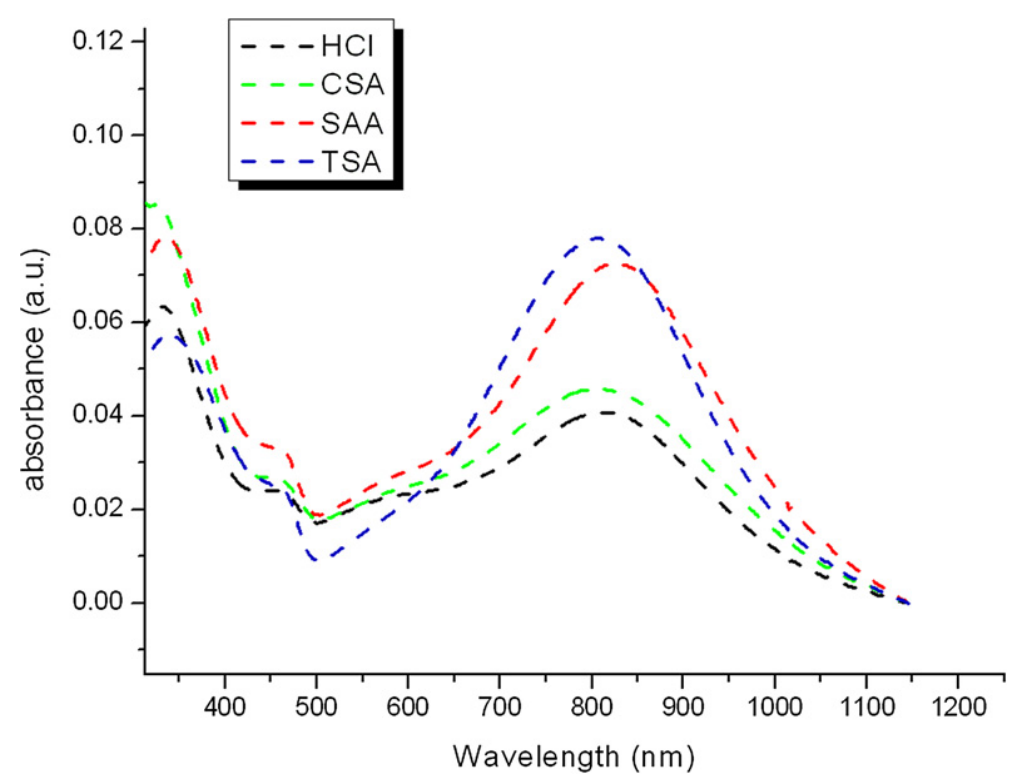

Fig. 8. (a) UV-vis absorbance spectra of POEA films (1 layer of $3 \mathrm{~min}$ ) doped with different acids in $\mathrm{pH} 3.0(C=0.6 \mathrm{gL}-1)$.

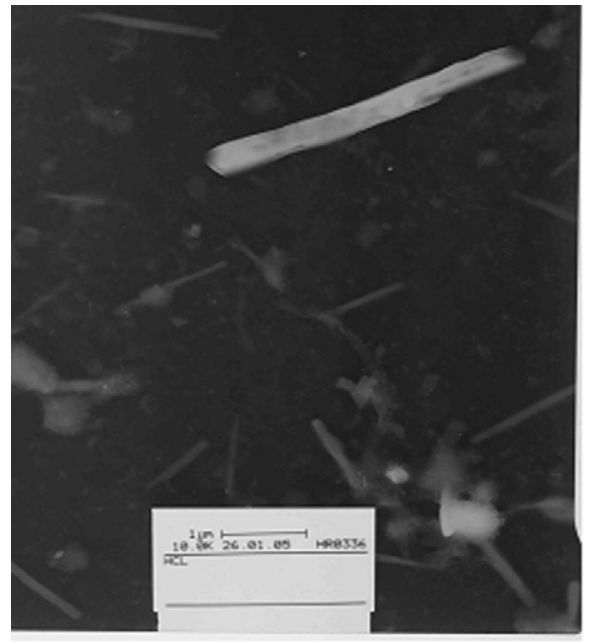

(a)

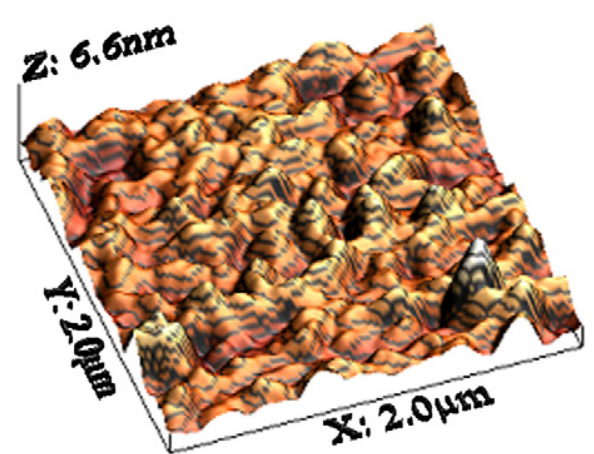

(b)

Fig. 9. (a) TEM micrograph of POEA doped with TSA and (b) AFM image of POEA in emeraldine salt state, doped with TSA.

would lead to a more compact conformation of the polymer, thus resulting in a larger amount of material adsorbed [67-69].

The larger amount of deposited material for POEA doped with TSA and SAA (Fig. 8) in comparison with another organic acid (CSA) can be explained by the large radii of gyration in solution. The differences observed on the amount of POEA adsorbed in films prepared with different acids are, analogously to the different radii of gyration, due to the different degrees of association between the charged polymer chains and the counterions from the doping acids. As mentioned before, the counterions of organic acids should be less solvated in water, interacting more strongly with the polymeric chains. The electrostatic repulsions between polymeric chains are therefore minimized, which allows the chains to assume a more compact conformation and reach the substrate surface. Both effects are believed to increase the amount of POEA adsorbed. The opposite is found when the counterions are effectively dissolved in water and the polymeric chains are in a more extended conformation. The stiffness of the chains is caused by strong intra molecular electrostatic repulsion, which also hampers adsorption of polymeric chains onto the substrate. Consequently, smaller amounts of POEA are expected to adsorb.

The film morphology also depends on the doping acid, as illustrated in the TEM micrograph of Fig. 9. The films normally display a globular morphology, with larger globules and higher roughness for those doped with inorganic acids, e.g., $\mathrm{HCl}$. One exception is noted, though, for the film of POEA processed with TSA, for which a cylindrical morphology was observed (Fig. 9a). These well-defined cylinders may arise from the drying process in ultra-high vacuum (UHV) and treatment in an ultrasound bath. Electron diffraction analysis showed that POEA cylinders are amorphous, analogously to that observed for stretched amorphous polymers [70]. This cylindrical morphology is difficult to visualize with AFM because resolution is 


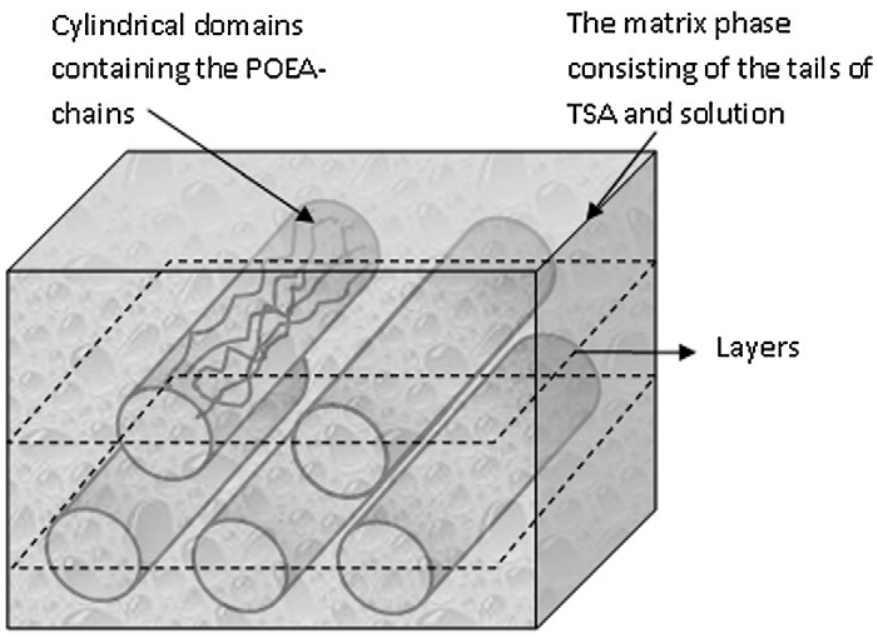

Fig. 10. Schematic view of the cylindrical brush conformation where the cylinders contain POEA (TSA) chains.

lost due to the tip radius $(\approx 50 \mathrm{~nm})$. Still, a quasi-fibrillar morphology was observed in Fig. 9b.

The result in Fig. 9 should be expected on the basis of the SAXS measurements discussed in Section 3.1. The morphological structure at the surface can be attributed to the intrinsic "comb-like" molecular architecture of the POEA-TSA system in solution, which forces the polymer chains to adopt the conformation of cylindrical brushes, similar to those of PANI(AMPSA) $0.5\left(\mathrm{C}_{n}\right.$ res) samples [71]. This conformation is caused by the steric overcrowding of toluenesulfonate anions which remain close to POEA cation radical segments due to their lower solubility in water. These features are depicted in a proposed model for the morphology, shown in Fig. 10, in which the distance between two neighboring layers corresponds to the distance between two neighboring POEA chains. Considering (as an extreme case) that a fully extended POEA backbone with 120 monomers units has $\sim 1002 \AA$ [72] for the chain contour length, we conclude that the objects appearing within the lamellae in the picture of Fig. 10 are indeed small molecular aggregates. Such features are similar to polyaniline nanotubes $[73,74]$, whose electronic properties are size dependent. This opens the way for developing new materials for devices with tailored characteristics. Some structures shown in Fig. 9 have a diameter of a few nanometers, typical of nanotubes, but the diameter may reach $500 \mathrm{~nm}$. The cylindrical structures found here are highly irregular in size as they were produced by dropcasting, rather than using controlled film fabrication processes such as the arc-evaporation method or chemical vapor deposition (CVD) [75].

\section{Conclusions}

The combination of SAXS measurements of polyanilines in solutions and AFM imaging for adsorbed, nanostructured films allowed us to infer that film morphology for short adsorption times is governed by aggregation in solution. Indeed, estimates of the size of the globules in the films led to similar values to those of the size of the aggregates of the polymer molecules in solution. At higher adsorption times, film formation was accompanied by further aggregation until eventually a less rough film was formed at ca. $180 \mathrm{~s}$ of immersion. Thus, the AFM images represent an "off print" of the solution conformation when molecules are adsorbed on the substrate. Significantly, the shape of the aggregates in solution depended on the $\mathrm{pH}$, as expected from the different degrees of doping.

SAXS offers an effective tool for determining the fractal dimension of aggregates of particles. The fractal dimension of particles formed by diffusion-limited process (DLCA) (i.e., fast aggregation) was in the range 1.4-1.8 for PANI-EB and its derivatives. At low $\mathrm{pH}$, the fractal dimensions ranged from 1.9 and 2.7. The POEA and POMA values agree with findings in the literature, for which the fractal dimension is 2.1-2.2 for reaction-limited aggregation (RLCA). With the SAXS experiments we showed that the changes in conformation of polymer molecules in solution can be successfully reconstructed by an ab initio procedure.

Also investigated was the influence of the doping acid for POEA. Interestingly, POEA doped with TSA exhibited cylindrical aggregates in solution, which was then manifested as a cylindrical morphology in the adsorbed films studied by TEM. We demonstrated that the chains stacking can be described by a lamellar-like arrangement of cylindrical structures. This approximation enabled us to extract information on structural parameters which can be useful in designing nanostructures such as nanotubes and nanoparticles.

\section{Acknowledgment}

This work was supported by CNPq, IMMP, Fapesp, and LNLS (Brazil).

\section{References}

[1] R.J. Waltman, J. Bargon, Can. J. Chem. 64 (1986) 1433.

[2] T. Ahuja, I.A. Mir, D. Kumar, Rajesh, Biomaterials 28 (2007) 791.

[3] M. Jaiswal, R. Menon, Polym. Int. 55 (2006) 1371.

[4] M.J. Breton, Macromol. Sci. Rev. Macromol. Chem. Phys. C 21 (1981) 61.

[5] O.V. Chechel, E.M. Nikolaev, Instrum. Exp. Tech. 67 (1991) 750.

[6] J.C. Huie, Smart Mater. Struct. 12 (2003) 264.

[7] J.S. Lindsey, New J. Chem. 15 (1991) 153.

[8] K. Wohnrath, J.R. Garcia, F.C. Nart, A.A. Batista, O.N. Oliveira Jr., Thin Solid Films 402 (2002) 272.

[9] K. Wohnrath, C.J.L. Constantino, P.A. Antunes, P.M. dos Santos, A.A. Batista, R.F. Aroca, O.N. Oliveira Jr., J. Phys. Chem. B 109 (2005) 4959.

[10] S.H. Yang, J.T. Chen, A.K. Li, C.H. Huang, K.B. Chen, B.R. Hsieh, C.S. Hsu, Thin Solid Films 73 (2005) 477.

[11] R. Murugesan, E. Subramanian, Mater. Chem. Phys. 80 (2003) 731.

[12] Z. Ping, G.E. Nauer, H. Neugebauer, J. Theiner, A. Neckel, J. Chem. Soc. Faraday Trans. 93 (1997) 121.

[13] A.A. Pud, M. Tabellout, A. Kassiba, A.A. Korzhenko, S.P. Rogalsky, G.S. Shapoval, F. Houze, O. Schneegans, J.R. Emery, J. Mater. Sci. 36 (2001) 3355 .

[14] E.C. Venancio, L.G. Paterno, C.E. Borato, A. Firmino, L.H.C. Mattoso, J. Braz. Chem. Soc. 16 (2005) 558.

[15] E.M. Paul, A.J. Ricco, M.S. Wrighton, J. Phys. Chem. 89 (1985) 1441.

[16] J.J. Langer, Synth. Met. 36 (1990) 35.

[17] K. Xu, L.H. Zhu, H.Q. Tang, Electrochim. Acta 52 (2006) 723.

[18] N. Gupta, S. Sharma, I.A. Mir, D. Kumar, J. Sci. Ind. Res. 65 (2006) 549.

[19] D.H. Zhang, Y.Y. Wang, Mat. Sci. Eng. B 134 (2006) 9. 
[20] V.V.R. Sai, S. Mahajan, A.Q. Contractor, S. Mukherji, Anal. Chem. 78 (2006) 8368.

[21] F.L. Leite, L.G. Paterno, C.E. Borato, P.S.P. Herrmann, O.N. Oliveira Jr., L.H.C. Mattoso, Polymer 45 (2005) 12503.

[22] J.M.G. Laranjeira, E.F. da Silva, W.M. de Azevedo, E.A. de Vasconcelos, H.J. Khoury, R.A. Simão, C.A. Achete, Microelectron. J. 34 (2003) 511.

[23] V.V. Shevchenko, L.V. Yemelina, Y.A.L. Kogan, G.V. Gedrovich, V.I. Savchenko, Synth. Met. 37 (1990) 69.

[24] G. Decher, J.D. Hong, Makromol. Chem. Makromol. Symp. 46 (1991) 321.

[25] G. Decher, J.D. Hong, Ber. Bunsen-Ges. Phys. Chem. Phys. 95 (1991) 1430.

[26] G. Decher, J.D. Hong, J. Schmitt, Thin Solid Films 210 (1992) 831.

[27] W.B. Stockon, M.F. Rubner, Macromolecules 30 (1997) 2717.

[28] M. Campos, B. Bello Jr., Synth. Met. 60 (1993) 1.

[29] M. Ruokolainen, G.T. Brinke, O. Ikkala, Macromolecules 29 (1996) 3409.

[30] C.Q. Jin, M. Park, Synth. Met. 124 (2001) 443.

[31] L.H.C. Mattoso, S.K. Manohar, A.G. McDiarmid, A.J. Epstein, J. Polym. Sci. A 33 (1995) 1227.

[32] M.G. Han, S.K. Cho, S.G. Oh, S.S. Im, Synth. Met. 53 (2002) 126.

[33] G. Porod, Small Angle X-Ray Scattering, Academic Press, London, 1982.

[34] D.I. Svergun, H.J. Koch, Curr. Opin. Struct. Biol. 12 (2002) 654.

[35] M. Kotlarckyk, S.H. Chen, J. Chem. Phys. 79 (1983) 2461.

[36] O. Glatter, O. Kratky, Small Angle X-Ray Scattering, Academic Press, London, 1982.

[37] D.I. Svergun, J. Appl. Cryst. 24 (1991) 485.

[38] D.I. Svergun, Biophys. J. 76 (1999) 2879.

[39] M.B. Kozin, D.I. Svergun, J. Appl. Cryst. 34 (2001) 33.

[40] W. Humphrey, W. Dalke, K. Schulten, J. Mol. Graph. 14 (1996) 33.

[41] N. Rosa-Fox, L. Esquivias, A.F. Craievich, J. Zarzycki, J. Non-Cryst. Solids 121 (1990) 211.

[42] D. Bagchi, R. Menon, Chem. Phys. Lett. 425 (2006) 114.

[43] A.V. Semenyuk, D.I. Svergun, J. Appl. Cryst. 24 (1991) 537.

[44] A.G. McDiarmid, E.J. Epstein, Synth. Met. 69 (1995) 85.

[45] Y. Haba, E. Segal, M. Narkis, G.I. Titelman, A. Siegmann, Synth. Met. 110 (2000) 189.

[46] M.G. Han, S.K. Cho, S.G. Oh, S.S. Im, Synth. Met. 126 (2002) 53.

[47] M. Sniechowski, D. Djurado, B. Dufour, P. Rannou, A. Pron, W. Luzny, Synth. Met. 143 (2004) 163.

[48] A. Eftekhari, M. Kazemzad, M. Keyanpour-Rad, Polym. J. 38 (2006) 781.
[49] D.W. Schaefer, K.D. Keefer, Phys. Rev. Lett. 53 (1984) 1383.

[50] D.W. Shaefer, Science 243 (1989) 1025.

[51] H. Boukari, L.S. Lin, M.T. Harris, Chem. Mater. 9 (1997) 2376.

[52] S. Neves, C. Polo Fonseca, Electrochem. Commun. 3 (2001) 36.

[53] D.A. Weitz, M. Oliveira, Phys. Rev. Lett. 52 (1984) 1433.

[54] W.C.K. Poon, M.D. Haw, Adv. Colloid Interface Sci. 73 (1997) 71.

[55] D. Asnagui, M. Carpineti, M. Giglio, M. Sozzi, Phys. Rev. A 45 (1992) 1018.

[56] A.Y. Kim, J.C. Berg, Langmuir 12 (2000) 2001.

[57] A.Y. Kim, K.D. Hauch, J.C. Berg, J.E. Martin, R.A. Anderson, J. Colloid Interface Sci. 260 (2003) 149.

[58] A.M. Puertas, A. Fernandez-Barbero, F. de Lãs Nieves, J. Colloid Interface Sci. 265 (2003) 36.

[59] A. Eftekhari, M. Kazemzad, M. Keyanpour-Rad, Polymer J. 38 (2006) 781.

[60] W. Wu, J.Y. Huang, S.J. Jia, T. Kowalewski, K. Matyjaszewski, T. Pakula, A. Gitsas, G. Floudas, Langmuir 21 (2005) 9721.

[61] G.R. Bushell, G.S. Watson, S.A. Holt, S. Myhra, J. Microsc. 180 (1995) 174.

[62] C. Bustamante, J. Vesenka, C.L. Tang, W. Rees, M. Guthold, R. Keller, Biochemistry 31 (1996) 22.

[63] T. Thundat, X.Y. Zheng, S.L. Sharp, D.P. Allison, R.J. Warmack, D.C. Joy, T.L. Ferrell, Scanning Microsc. 6 (1992) 903.

[64] M.G. Han, S.K. Cho, S.G. Oh, S.S. Im, Synth. Met. 126 (2002) 53.

[65] L.G. Paterno, L.H.C. Mattoso, Polymer 42 (2001) 5239.

[66] L.G. Paterno, L.H.C. Mattoso, J. Appl. Polym. Sci. 83 (2002) 1309.

[67] M. Reghu, Y. Cao, D. Moses, A.J. Heeger, Synth. Met. 55-57 (1993) 5020.

[68] M. Angelopoulos, N. Patel, R. Saraf, Synth. Met. 55-57 (1993) 1552.

[69] K.J. Neoh, E.T. Tang, K.L. Tan, Polymer 35 (1994) 2899.

[70] L.E. Alexander, X-Ray Diffraction Methods in Polymer Science, WileyInterscience, New York, 1969.

[71] M. Tiitu, N. Volk, M. Torkkeli, R. Serimaa, G.T. Brinke, O. Ikkala, Macromolecules 37 (2004) 7364.

[72] F.L. Leite, C.E. Borato, W.T.L. da Silva, P.S.P. Herrmann, O.N. Oliveira Jr., L.H.C. Mattoso, Microsc. Microanal. 13 (2007) 304.

[73] H. Xiai, H. Sze, O. Chan, C. Xiao, D. Cheng, Nanotechnology 15 (2004) 1807.

[74] Z. Wei, M. Wan, T. Lin, L. Dai, Adv. Mater. 15 (2003) 136.

[75] M. José-Yacaman, M. Miki-Yoshida, L. Rendón, J.G. Santiesteban, Appl. Phys. Lett. 62 (1993) 657. 